\title{
Current developments in library cooperation among special libraries in Botswana
}

\author{
Chedza Molefe \\ Chief Librarian, Botswana Institute for Development Policy Analysis (BIDPA), \\ Private Bag BR-29, Gaborone, Botswana \\ Chedza@bidpa.bw
}

Received: $17^{\text {th }}$ May 2002

Revised : $27^{\text {th }}$ October 2002

\begin{abstract}
Library consortia and formal resource sharing though commonplace in some parts of the world, are not developed in Botswana. Librarians have operated on informal networks in the facilitation of resources sharing especially in the form of Interlibrary Loans (ILL). One group of librarians are advocating for the formation of a nationwide library consortium to overcome cost of licensing fee for electronic databases. Librarians working for special libraries in Gaborone, the capital city of Botswana are planning to form a consortium for special libraries. Their vision is to develop a full text database of information produced in Botswana in the subject areas that the libraries represent. It is hoped that more special libraries will join in and that the database will be a base for a national full text database that will help narrow the digital divide between the global North and South. The database will also preserve national indigenous information and ease its accessibility. Challenges facing the group include lack of funds and lack of expertise. A proposal will be drafted to source funds from donors and external expertise will be sought.
\end{abstract}

Key Words: Library Cooperation-Botswana; Library Consortia-Botswana; Library Consortium-Botswana Information Resource Sharing; Digitization Projects; Special Libraries

\section{Introduction}

Library cooperation is not a novel idea. Nfila and Darko-Ampem (2002), studying the developments in academic library consortia, trace the origins of library cooperation to the times of Melvil Dewey who wrote on the subject as early as 1886. Botswana special libraries, now seeking to establish library cooperation, have a lot of lessons to drawn from. A variety of terms have been used to refer to the act of working together for the benefit of all concerned. In the literature dealing with library cooperation a variety of words are used to define collaborative efforts. Brodie (1996) notes that "Some of these are "action" words, such as connect, consult, cooperate, collaborate, collude; and "organization"and others refer to, for example, conference, committee, coalition, consortium, corporation, community. The beginning of all of these words comes from the short form of the Latin "with". Despite different shades of meaning, such as degree of engagement or social acceptability, these words always suggest the coming together of distinct parties to achieve a common end, in activities usually limited in time or space. In general, the participants in such activities maintain distinct roles and remain "in control" of the situation". The latest addition to these words is networking. This term has become inclusive encompassing relations or communications between machines and that between professionals with common interests. Martey (2002, p. 239) writes "Networking has been defined as a group of organizations that are formally interconnected, or participate with each other, for the accomplishment of predetermined objectives and having an organizational structure".

In the APT review of 1995, library cooperation is defined as:

the creation and operation of equitable, that is mutually 'fair', collaborative arrangements between libraries and information providers which enhance the common good through making information available to all potential users (without obstacle to access by reason of cost) which is more extensive or more valuable to the user and/or is of lower cost to the collaborating providers.

The APT review further observes that library cooperative activity may seem to represent a comparatively small part of total library and information activity but it is of vital importance. The current information environment necessarily calls for concerted efforts to meet the needs of users with ever growing demands driven by change which has become a norm rather than something to marvel at. Emphasizing the importance of cooperation, the APT review states that: "Libraries of all kinds will have to grasp the partnership nettle if they are to thrive in the next Millennium. Even the British Library is now developing a cooperation strategy as it realises that it can't continue to go it alone..."

Gillham (1996) concludes that "In contemplating collaboration, it is essential to think long term and to think strategically. Collaboration is not a quick fix to immediate problems. Collaboration is not just an economic strategy: this is not really about money. The primary and enduring reasons for a collaborative approach are the many positive benefits which will be experienced by those we are here to serve" 
Library cooperation includes a series of long term activities that need careful planning to ensure their future sustainability. All librarians participating in the collaborative effort need to appreciate the need and advantages of such cooperation. The participating librarians, the mother organisations and primary clients need to have a clear perspective of the operations of the cooperation as perceived if the partnership has to succeed. Among other reasons, failures recorded show that sometimes there have been bottlenecks due to urges to compete, unwillingness to evolve and sheer tendency to control rather than consult within a partnership. A collaboration agreement obviously introduces organizational change which penetrates the entire institution. Participants should anticipate and expect change and to be prepared for it. Gillham (1996) observes that collaboration should breed a "sense of stewardship ... in which the care of the whole is considered, not just the individual institution. When an issue arises, the first question should be" what does this mean for the consortium?" not "what does this mean for my library?"

Small libraries serving specific clientele, information resource centres in specific organisations, research libraries serving researchers with a clear subjects or subject foci and libraries in government department are, for the purposes of this paper, referred to as special libraries. Most of these libraries are open to the public as well as serving their primary users. This indicates that the information in these libraries is not strictly restricted. However, by their very nature, being small libraries, it is difficult for them to offer full user rights including borrowing to the public. In these libraries circulation control including collecting overdues and disciplining delinquent users may not be feasible given the staff compliment. Currently preliminary discussions on library cooperation are going on including the following libraries: Botswana Institute for Development Policy Analysis (BIDPA) Library, Bank of Botswana (BOB) Library, Botswana Technology Centre (BOTEC) library, Botswana National Productivity Centre (BNPC) library, Madirelo Training and Testing Centre (MTTC) library, Botswana Bureau of Standards (BOBS) Library, Central Statistics Office (CSO) Library, Emang Basadi Documentation Centre, Southern African Development Community (SADC) library, Institute of Development Management (IDM) and Roads Training Department library. It is possible that more similar libraries to the ones above will come on board at a later stage. All the libraries and information centres that are involved in this emerging cooperation are autonomous and operating under different guidelines and rules which will have to be rationalized in forming the consortium without prejudicing or undermining the autonomy of each one. The one area which these libraries differ significantly is how each, offers borrower rights and privileges as reflected in Table I.

Table I. Loan privileges to various user categories

\begin{tabular}{llll}
\hline Library & Loans to clients & & \\
\hline & Organisation staff & External Borrowers & Other libraries \\
\cline { 2 - 4 } BIDPA & Yes & Yes. Affiliated only & Yes \\
BoB & Yes & No & Yes \\
BOTEC & Yes & Yes & Yes \\
BNPC & Yes & Yes. Paying & No \\
MTTC & Yes & No & No \\
Emang Basadi & Yes & No & Yes. Negotiable \\
SADC & Yes & Yes. Librarians discretion & Yes \\
Roads Training Department & Yes & & No \\
BOBS & Yes & No & No \\
CSO & Yes & No & Yes \\
IDM & Yes & Yes. Librarian's discretion & \\
\hline
\end{tabular}

Furthermore, these libraries vary in resources including infrastructure and staffing levels and capacity. Staff, equipment and financial resources are the main ingredients for library cooperation and participating partners will, therefore, depend largely on the current staff capacity, readily accessible financial resources to lay the foundation for the library collaborative activities. Table 2 presents a summary of resources available at different member libraries of the proposed cooperative venture. The table illustrates staff capacity, advancement in automation and IT equipment. 
Table 2. Resources at different libraries

\begin{tabular}{|c|c|c|c|c|c|c|c|}
\hline Library & Staffing & & Stage in Automation & IT inf & astructure & & \\
\hline & Professionals & Paraprofessionals & & PCs & Printers & Scanners & $\begin{array}{l}\text { Internet } \\
\text { access }\end{array}$ \\
\hline BIDPA & 2 & । & Fully Automated using ADLIB & 3 & 0 & 1 & 4 \\
\hline BoB & 1 & 1 & $\begin{array}{l}\text { Fully Automated using ADLIB } \\
\text { Semi-automated using CDS/ISIS } \\
\text { (Computereised Documentation } \\
\text { Service/Integrated Set of Information } \\
\text { Systems) }\end{array}$ & 3 & । & 1 & 4 \\
\hline BNPC & 1 & 1 & $\begin{array}{l}\text { Currently migrating to LIBWIN } \\
\text { Automated } \\
\text { CDS/ISIS now upgrading to WIN/ISIS }\end{array}$ & 4 & । & I & 4 \\
\hline SADC & I & I & (Windows version of CDS/ISIS) & 3 & । & 0 & 4 \\
\hline BOTEC & 1 & 2 & $\begin{array}{l}\text { Automated using an In-house system. } \\
\text { Library automated using CDS/ISIS. }\end{array}$ & 6 & 2 & 0 & 4 \\
\hline $\begin{array}{l}\text { IDM } \\
\text { Roads }\end{array}$ & 1 & 2 & Looking for a new system & 2 & 2 & 0 & 4 \\
\hline Library & I & 1 & Automated using Inmagic & 2 & I & 0 & 4 \\
\hline $\mathrm{CSO}$ & & I & Not automated & I & 0 & 0 & 4 \\
\hline BOBS & I & 1 & $\begin{array}{l}\text { Not automated. Looking for a new } \\
\text { system }\end{array}$ & 3 & 2 & 0 & \\
\hline $\begin{array}{l}\text { MTTC } \\
\text { Emang }\end{array}$ & 0 & I & Only a list in Access & 1 & I & 0 & 4 \\
\hline Basadi & 1 & 0 & Not automated & 3 & 1 & I & 4 \\
\hline
\end{tabular}

All libraries without printers are connected to printers on organization's Local Area Network

All libraries so far involved in the discussion have at least Internet connectivity. This means that Internet can be exploited to propel information delivery between cooperating partners and beyond. Full text database can be created and kept in one central server which can be accessed via an extranet with password access control. Participating libraries could be able to retrieve information on a normal browser interface.

Various libraries also have different strengths in their in-house collections and access capacities. BIDPA has a strong collection on Economic planning, poverty and Welfare, Incomes, HIV/AIDS and its economic impacts, Trade, Labour economics (including employment and unemployment), Financial economics (banking, inflation, wages, income), Government policy analysis and monitoring, Macroeconomics and Public administration. The Bank of Botswana Library on the other hand, has information pertaining to Banking Economics, Financial Economics, Financial Statistics, Fiscal Planning, Investment, Macroeconomics, Money Markets and Monetary Policy. The same library also holds an extensive array of IMF and World Bank publications. IDM, on the other hand specializes in Management including Business Management, Human Resource Management, Information Management and Public Administration. MTTC library holds good collections on Plumbing, Electronic Engineering, Bricklaying and Painting, Welding, Fitting, Textile, Carpentry/wood technology and Computer science. BOTEC is strong in science and technology fields including Energy and Power, Water Sanitation and Water disposal, Agriculture, Aquaculture, fisheries and Forestry, Food Technology and Processing, Manufacturing and Engineering Services and Human Settlements Habitat, Construction and Building. The Central Statistics Office (CSO) of the Ministry of Finance and Development Planning documentation centre has expressed interest in participating in the discussions to initiate cooperation. The CSO has an unparalleled collection of statistical data on both the local and regional level.

\section{Current problems in accessing local information}

Major problems faced by researchers and librarians trying to select and gather information include lack of identifiable point of output, out of print books and out of stock sources. Problems in information access in Botswana are propounded by the ill developed book industry especially the publishing component. Some writers seem to lack confidence in the available publishers to the extent of trying to operate the entire process themselves. A good example has been that of a 
locally produced publication entitled Mogwebi/the trader: a do-it-yourself guide for small business produced and publicized by Motlhalefi Kgaboesele in 1996. The book's existence was announced in one of the local newspapers and the author marketed and distributed it himself. Such publications do not reach a wide audience. Mogwebi/the trader: a do-it-yourself guide for small business is a locally produced publication containing information whose relevance is significantly promoted by the current government citizen economic empowerment and poverty alleviation programmes. The book is tailormade for the local scene and written in both English and the local national language (Setswana). It is a book that should have reached all libraries and some people for personal copies.

Government publication present unique problems due to the processes used in the production and dissemination of such publications. It is not always obvious that all non-confidential non restricted government publications will be available from the government printer bookshop which is the main distributing unit for government publications. The print-runs are always limited and once there are out of stock they are almost never reprinted. The government printer has a publishing wing that produces the publications. Upon completion of the work the printer takes the entire load back to the government department responsible which in turn returns some copies for distribution in the bookshop. Sometimes publications do not make it to the book shop at all.

In 1996, the Botswana Institute for Development Policy Analysis (BIDPA) library helped Botswana Society to compile a bibliography of information sources that discuss quality of life in Botswana and related subjects. As part of the exercise, visits were made to libraries around Gaborone to search for the relevant subject areas. The result was a database carrying a lot of bibliographic information of sources relevant to the study. Records from the database have since been merged into the library database. Initially it was hoped that the actual sources will be acquired to compliment BIDPA's library holdings. Attempts to collect these sources proved to be futile for most of the registered publications. The documents are either out of print or in some cases their real point of output cannot be determined.

Another example of a publication that was not easy to acquire was the report produced by BIDPA for the Ministry of Finance and Development Planning, Study of Poverty and Poverty Alleviation in Botswana (BIDPA 1997). The report became a very popular publication shortly after its production. BIDPA received numerous enquiries which were all referred to the ministry. Most researchers got frustrated and kept coming back to BIDPA after their numerous efforts to acquire this publication were fruitless. The document was published in 1997 and has now become a rare commodity with no clear indication that it will ever be readily available.

The other aggravating factor is that most locally produced literature never finds its way to internationally available databases. Searching for Botswana literature in EBSCOHOST, Igenta, ELDIS or any of the other online databases including CD-ROM based bibliographic databases is like looking for puddles in a desert.

There are two legal depository libraries in Botswana namely: - Botswana National Library Service and The University of Botswana Library. It has become common practice for some to submit a copy to the National Archives as well. The National Library Services chapter (Chapter 58:2), section 10 of the Laws of Botswana stipulates that:

The publisher of every book published in Botswana shall, within one month after the day on which such a book is first delivered out of the press, and not withstanding any agreement to the contrary with any person, deliver at his own expense- (a) one copy of the book to the Librarian of the University of Botswana; (b) two copies of to the Chairman of the Board of the Botswana National Library services or such person and place as the Board may direct.

Researchers experience access problems to documents housed in these locations. Sometimes publications are either not available or when available there are in closed access or restricted access points. The legal deposit law, itself, is too loose to catch all Botswana produced documents; The fine for none compliance is P50.00 (US\$ 8.05) or less which can hardly be a deterrent, the law does not make any mention of author's responsibility instead it binds the publisher hence any unpublished work falls outside the legal net. Both the University and the National Libraries sometimes find themselves having to buy documents that should have been encompassed in the legal regulation but has not been deposited for one reason or the other. Access to Botswana publications is limited and it is a major source of frustration for many researchers who find gaps in their literature searches.

Problems of access haunt smaller libraries even more. Librarians, knowing that their role is to provide information, are often frustrated when researchers come to them for help trusting that an information specialist should at least be able to retrieve or acquire items that are locally published and it proves impossible to get the required literary source. The special libraries are each rich in their own special areas although information on holdings is not always readily available or when it is, access is not guaranteed. Librarians have decided to work out a formalized cooperation to make holdings information available from the desktop of all partners and also guarantee access to such full text literature. 


\section{Genesis of cooperation among special libraries in Botswana}

In 1995, shortly after BIDPA's inception, the librarian invited other librarians from around Gaborone. The main objective of the invitation was to introduce the newly established research institute, BIDPA to the peers. The period was carefully selected because BIDPA library housed only empty shelves at the time. The information sources void was to be used to emphasise the need and importance of cooperation. A few BIDPA staff members from other departments had already started work. The executive director attended the meeting and welcomed the librarians to BIDPA. To conclude her speech, the librarian, told colleagues that although BIDPA researchers were beginning to work on some projects, and the library was empty, their information needs would need to be met expediatiously. She then pointed out that since librarians do not operate as islands, the BIDPA library would have to rely on access to resources from elsewhere more than on possession on acquisition. The group agreed that information resource sharing with each other would be a welcome improvement to individual libraries. It was observed that informal arrangements were prone to abuse and bound to cause problems amongst borrowing and lending libraries. The idea to form a formalized consortium was mooted.

Resource sharing in itself is not a novel idea in Botswana and the tradition of resource sharing is an ancient one in the library profession. Formal library cooperation in the form that we see today, dates back to the late 1930s. Buckley (1999) states that 'Formal cross-sectoral cooperation started in the 1930s with the setting up of 9 Regional Library Systems (RLS) for inter-lending and catalogue-sharing.' The 1990s, however, witnessed unprecedented and innovative activities in resource sharing. This was due to the ease with which libraries were able to communicate propelled by Information Communication Technology (ICT). Library cooperation has become common both in the developed and the developing countries. Some African countries including Botswana's neighbours, South Africa and Zimbabwe (Sander, 2002) have some well established collaborative activities. South Africa boast of several developed structures similar to ones found only in the developed countries. Several library consortia in South Africa are drawn together under the umbrella of Coalition of South African Library Consortia (COSALC). Members include the Cape Library Cooperative (CALICO), Eastern Seaboard Association of Libraries (eSAL), Free State Library and Information Consortium (FRELICO), Gauteng and Environs Library Consortium (GAELIC), South East Academic Library System (SEALS), National Executive Directors of Academic Consortia (NEDAC), Sabinet Online, European Union/Department of Education, National Library of South Africa (NLSA) and Library and Information Association of South Africa (LIASA)

Botswana, despite its reasonably developed communication infrastructure, is lagging behind in resource sharing endeavours. Reasons for the indifference maybe attributed to the general landscape of librarianship in the country. Major library services are heavily centralized and therefore already maintain the look and feel of consortia. The Botswana National Library Services (BNLS) is the national library and also the controlling body for all public libraries. The BNLS also heads other library services such as the Book Box Services, The Mobile Library Services, the Village Reading Rooms and it seconds staff to school libraries, college libraries and department libraries in government ministries. With only one university in the country, all academic library branches fall under the administration of the University of Botswana Library.

\section{Current collaborative efforts}

Library professionals are upbeat about the establishment of library cooperation or consortium in Botswana. A group of librarians is currently considering pooling resources together to facilitate access to the Open Society Institute (OSI) Electronic Information for Libraries Direct (EIFL) also known as EBSCOhost (Motlhabane, Ramore and Raseroka, 2002). The current annual license fee is a high cost for any single library. The Botswana delegation met with OSI representatives during the Standing Conference of African National and University Libraries in Eastern, Central and Southern Africa (SCANUL-ECS) meeting in Johannesburg in April 2002. The OSI representative and the Botswana participants discussed the vision of consortium building within Botswana. The Botswana representatives are now consulting widely within the country to initiate a nation wide consortium to obviate the high costs. It is envisaged that once the consortium has been formed, other areas of cooperation will be investigated.

As already discussed above, the academic, national and public libraries have some resemblances of consortia. Besides these major library services there are many special libraries that have predominantly remained isolated. Informal discussions about formation of cooperations or networks for the facilitation of resource sharing date as far back as before 1995. The Gaborone based librarians from special libraries had a meeting that discussed possibilities of cooperation. All indications were that librarians would in the near future get together to further chart a way and strategise on the formation of a collaborating team. The initial meeting went a long way in promoting professional networking, the formation of informal working relationships and trust. It, however, did not yield much in terms of formal library cooperation and resource sharing. Following the meeting, a proposal outlining areas of cooperation was written by the BIDPA executive director and the chief librarian (Isaksen and Molefe 1996). 
The Bank of Botswana (BOB) Library and BIDPA library, perhaps due to their closely related subject scope and content, have something to show todate. Following the meeting of the Gaborone based librarians from special libraries, BIDPA and BOB librarians, the BIDPA Executive Director and the BOB Director of Research met along with a few other representatives from the research departments of both sides to concretize their libraries cooperation. It emerged from the meeting that while BIDPA library had limited collections, BOB library held rich collections that only needed proper processing and reorganization to facilitate access and retrieval. BIDPA would, therefore rely to a significant extent on access to the BOB collections. Since BIDPA was better equipped in terms of qualified staff, BOB would tap into this knowledge to improve the library. The BIDPA/BOB library cooperation, therefore, entailed, library stock and staff sharing. BIDPA, then proceeded to reorganise and automate the BOB library catalogue. The two libraries began to share a library database which uses the ADLIB library system. To further develop the BIDPA/BOB cooperation, the Ministry of Finance and Development Planning (MFDP) and the Central Statistics Office (CSO) showed strong interest. The library at the ministry, however, had been closed down due to space constraints and library materials had been moved to the basement. The ministry was hoping to get more space through extension of the building in which case the library would be reinstated. CSO seemed to have problems with their setup which includes a librarian seconded by BNLS. The CSO staff was not clear whether they could make their own independent decisions or wait for BNLS to make such decisions for them. This led to the delay in CSO library joining in the collaborative library automation which formed the backbone for the BIDPA/BOB cooperation. BOB and BIDPA libraries currently share a library database which BOB accesses remotely from BIDPA. The other libraries fell out since there was no follow-up meeting or communication.

Cooperation between the Bank of Botswana library and BIDPA library has had several resources sharing points include shared automated services, staff and document deliveries. Both libraries use the ADLIB library automation system with the database residing at BIDPA. The automation system, features cataloguing module, circulation, serials, acquisitions module and an internet Public Access Catalogue (OPAC). All modules are accessible to both libraries in real time. Searching the database virtually gives results of both holdings. The actual document delivery has entailed the use of telephone and then drivers picking and dropping off materials or fax if the required item is an article.

Where staff capacity sharing is concerned, staff at BIDPA were contracted to reorganize and automate the BOB library. At the time, BoB library had two staff members, a paraprofessional and an unqualified member. BIDPA provided the required professional guidance, reviewed and updated classification and indexing of the existing collection to build a quality library database. After the end of the contract, BIDPA continued to lend a helping hand in difficult areas including the running of the computer system. The BoB library staff and others were trained on the use of the ADLIB system. (BIDPA 996).

The relationship between BIDPA and BOB has had some hiccups and standing problems especially in the area of technology. The document delivery system can be improved as will be discussed in the proposed areas for cooperation section of this paper. The automated system has caused a lot of problems for the remote site. BOB library uses a standard dial-up connection which is not very efficient for data transmission. At some point the librarian would carry a trolley load of library items to input from BIDPA for faster results. A better solution to the problem would be to use a two wire copper dedicated line with a dedicated modem which would offer a more reliable connection and handle data in a better manner. The other and best but expensive option would be to use an ISDN dedicated line which would have more speed and reliability Isaacs (1999) and Afriswitch (2001)

Besides the BIDPA/BOB relationship, BIDPA has also been able to share information sources with BNPC, BOTEC, CSO, the University library and IDM. These other relations are mainly dependent on understanding between two or more librarians of organizations involved at the time. For instance the BIDPA library often borrows materials from the BNPC library and vise-versa while the same may not be true between the BNPC and the SADC libraries or any other two from the group.

\section{Proposed areas of cooperation}

A successful cooperation should necessarily add value for library users at all participating partner libraries. The main object of the proposed cooperation is to give virtual access to libraries' holdings and also to the information held therein. A good indicator to holdings will be an excellent start but should not be an end. Modern technology has made it possible to view and actually access full text documents from remote locations. While the obvious objective of cooperation would be to cut costs by sharing computing facilities, the overall ambition of the cooperation should be to make documents accessible in electronic formats. It is proposed that the backbone of the special libraries cooperation in Botswana be the digitization of the relevant core collections especially of locally generated information.

The use of electronic or digital formats have alleviated problems of access to information in many countries of the world. Botswana Institute for Development Policy Analysis Library support and facilitates work carried out at the 
institute. Each collaborating library has special strengths. BIDPA's core business, for example, is policy analysis from several angles including, research, consultancy and training. The library strives and is expected to be a leader in the provision of related information. While BIDPA thrives to collect comprehensively in its core areas, it is not possible to catch all necessary sources. Some of the reasons are that BIDPA library was established in 1995 and in some cases researchers need to look back into history beyond that date to put their research into perspective. Due to problems already discussed, it is difficult to acquire materials published in Botswana from those back dates. The Bank of Botswana will have more of such materials in their areas and the same goes for other libraries because they were already in existence when the items were published. The envisaged library cooperation and resource sharing will ensure that all information available in one location is available to the other partners.

Many libraries in Gaborone have practiced a gentlemen's agreement in resource sharing especially in the form of informal inter-library loans. Some of these librarians from special libraries have started discussions on the possibilities of forming a framework for formal cooperation. It is clear that this kind of cooperation will go beyond sharing library items only. The cooperation requires sharing of information technology equipment and also sharing expertise. Though these are not main areas of cooperation they are inevitable. There is need to know the participants in order to strategically pool capacity to the best advantage of the group and the library users.

\section{Expected outcomes}

The participating librarians' vision is that through the library cooperation, the special libraries in the partnership's access to locally produced information will be made easy and just-in-time. Participating libraries and information resource centres will provide full text digital content including works that were originally digital as well as materials that existed in other formats and have been digitized. The collection will include a wide subject scope as determined by the subject diversity found in the partner libraries.

The project will focus on maximizing the exploitation of resources that are currently available at various sites. These include computing, human resources and internet connectivity. The project aims to bring together partners on a website that acts as a gateway to virtual collection with distinct specialized foci and in some cases, unique resources which mark such libraries as special in their subject scope and coverage.

With this cooperation, the partners anticipates a locally produced database of full text electronic documents produced locally. The primary use of the database will be to serve the library users of all participating libraries. The ambition for the database is to be a foundation for a national digital document bank. The product is envisaged as a small but significant start towards bridging the digital divide between Botswana and other countries and also in improving access to indigenous information.

\section{Probable challenges}

Entering into collaboration is a commitment. As such, all participants have to understand all responsibilities, obligations, commitments, benefits and expectations. All these have to work in a fair and consistent manner to all participants. A documented framework has to be put in place to ensure adherence to agreed standards and identity. The group has to address the question of identity. Is the group going to operate as an informal gathering? Is it going to register as an independent body? Or is it going to operate under the auspices of an already existing professional body? Who provides leadership? Such are questions that need to be answered to start on a good footing. When all answers have been provided, they is need to draft a memorandum of understanding to document the business relationships between the participating members, including the rights and responsibilities of membership; Draw up strategic plans to chart the way forward. Strategic planning is the backbone of the collaboration efforts and it is through such plans that a consortium will succeed. Sloan states that strategic plans '... offer a good look into the 'soul' of a consortium'.

Library cooperation necessarily brings about change in all aspects of work of the participating librarians. Change needs to be managed if it has to be effectively implemented. Activities introduced by collaboration are necessarily additions over and above which will have impact on all resources deployment including budget and staff. It is noted that in order for the conceived Botswana special libraries cooperation to succeed, the human resources with expertise, understanding and commitment is crucial and at the early stages it is difficukt to gauge people commitement. It is imperative that staff of the participating libraries share a vision which will guide the collaboration and focus its activities. There will be cost implications that have to be determined monitored and directed in a way that moulds the cooperation activities to reflect and maintain the cost-effectiveness perceived with resource sharing. It is worth mentioning, however, that the great advantage in the formation of library cooperation is the improved service rather than money saved. The beginning of the cooperation will necessarily cost more than current running costs combined. There are, however still two overall expectations from the cooperation; easier information access and the maintenance of cost effectiveness of service. 
The special library cooperation is an ambition that will need to be realized. There are some real challenges that librarians have to deal with and find solutions to. The only reality and driving force behind all activities is the vision to which all concerned subscribe. A few obstacles that need to be overcome are: staff limited knowledge of digitization projects, lack of sample projects in Botswana and lack of funding and the general lack of confidence by donors in small organisations, low profile of libraries within organistions. Most libraries always suffer the most whenever organisations have a need to cut budgets. This is mainly because people in charge of the organizational budget barely understand the broad role of the library. The group has to figure out how to get funding for the cooperation project and possibly to think about getting external funding. External donors may want to deal only with big libraries such as the University library and BNLS while these may not share the exact same ambitions that special libraries have.

\section{The way forward}

The one way to go beyond the obstacles is to first and foremost understand and be convinced that the project is worth all efforts. The group, with clearly articulated vision, aim and objectives should be able to convince donors that such a project is a viable and will add quality and not only to the participating libraries's services but add a new dimension to the Botswana information provision scenario. The group may want to consider the programs of donors and sponsors such as United Nations Educational, Scientific and Cultural Organization (UNESCO), Information for Development Program (InfoDev), International Network for the Availability of Scientific Publications (INASP), the International Federation of Library Associations and Institutions Advancement of Librarianship (ALP), Commonwealth Library Association (COMLA) and possibly the Bill and Melinda Gates Foundation and others to find they are prospects for getting some of them interested in the project.

There is some limited staff expertise within the group. To succeed, however the group will have to outsource some of the activities towards the realization of the goal. External help will be sought for training as well to ensure the sustainability and future growth of the project. It will be necessary to seek help from libraries that have worked on similar projects. The beginning of the project will require rigorous learning programmes which may include visits and observation, workshops facilitated by knowledgeable individuals or contractual agreement with an expert to help lay the foundation.

\section{Conclusion}

Library cooperation and resource sharing is a popular topic for discussion among Botswana librarians. At national level, librarians are discussing the formation of a consortium to share costs of subscriptions to online databases, especially EBSCOHOST. Recently the Botswana delegation to SCANUL-ECS in South Africa had a meeting with the representatives of the OSI who proposed the country wide consortium through which subscriptions to databases in EBSCOHOST will be negotiated. Participants are now following up the lead to concretize the collaboration. Smaller libraries in the country have a vision to create full text content and be able to disseminate such locally produced, published or unpublished information to information seekers especially researchers.

The intended product will go a long way to bridge the digital divide and enhance accessibility to indigenous information. It will be an asset to both the librarian and the researcher. It will be an innovative initiative in Botswana and it is likely to accord the much needed recognition not only to the special libraries but also to the library profession in general.

Libraries and the library profession in Botswana do not have a high profile in their organisations. This low regard for librarians is manifested through a number of indicators such as librarians often having to fight to have access to whatever resources there are at the institutions disposal (A librarian for a training centre of a local organization was instructed by the Training Coordinator to pack all library materials into boxes and serve users from there so as to use the library as a classroom (BLA Executive Discussion Group 200I), the quick hand to cut the library budget when institutional finances are not in abundance, deployment of ill qualified or unqualified people in the library after which they are labeled librarians. The visibility of the cooperating group is necessarily more than the solo libraries efforts. A united group will be in a position to discuss and take decisions that have far reaching impacts. The broad based information pool accessible through each library obviously increases prominence among stakeholders and it is through this impact that libraries may leverage to gain mileage.

The main obstacles to achievement of the set goals are finance and expertise. For solutions to both problems, librarians will have to turn to external sources. Help can only be sought if the participants are clear in their vision and can articulate their needs, aim and objectives well enough to convince external parties. 


\section{References}

Afriswitch, 200I, Response to a request for leased wireless access solution. Gaborone.

Apt partnership, 1995, The Apt review: a review of library and information co-operation in the UK and the Republic of Ireland. Sheffield, Library and Information Co-operation Council

BIDPA, 1996, Project on library cooperation between the bank of Botswana (BOB) and the Botswana Institute for Development Policy Analysis (BIDPA)

Botswana Government, 1989, Laws of Botswana : National Library Services chapter (Chapter 58:2). Gaborone.

Brodie, Maxine, 1996, Connected intelligence: the power of library collaboration. [online] Available: http://www.csu.edu.au/special/ raiss99/papers/mbrodie.html. (Accessed I5 Sept. 2002)

Buckley, Barbara, 1999, Library Cooperation and Partnerships in the United Kingdom: or How joined-up Government is leading to joined-up libraries [online] Available: http://www.csu.edu.au/special/raiss99/papers/bbuckley.html (Accessed I5 Sept. 2002)

Gillham, Virginia, Michael Ridley \& Murray Shepherd, 1996, Towards effective collaboration. [online] Availabe: http:// www.lib.uoguelph.ca/About-the-Lib/Lib-Initiatives/TUG-OUCC96.html . (Accessed I5 Sept. 2002

Isaacs, Leo, 1999, Recommendations for BIDPA/BOB communication link. Gaborone.

Isaksen, Jan \& Chedza Molefe, 1996, Project proposal : Cooperation between libraries and information systems in the area of economics and policy analysis. Gaborone.

Martey, A.K. 2002, 'Management issues in library networking: focus on a pilot library networking project in Ghana,' Library management, vol. 23, no 4/5, pp. 239-25I.

Motlhabane, Ratanang, Lesego Ramore \& Kay Raseroka. 2002. $5^{\text {th }}$ SCANUL-ECS conference report on resource sharing and cooperation in university and national libraries. Johannesburg.

Nfila, Reason Baathodi \& Kwasi Darko-Ampem, 2002, 'Development in academic library consortia from 1960s to 2000: a review of literature', Library management, vol. 23, no 4/5, pp. 203-2। 2.

Okerson, Ann, 2002, International coalition of library consortia. [online] Available: http://www.library.yale.edu/consortia. (Accessed I 5 Sept. 2002)

Sander, Hannie, 2002, Library cooperation in South Africa, with special reference to COSALC and the new Higher Education Restructuring Plan (presentation made at the SALLP orientation on 13 March 2002). Pretoria.

Sloan, Bernie, 2002, Library Consortia Documents Online. [online] Available: http://www.lis.uiuc.edu/ b-s/oan/consort.htm (Accessed 15 Sept. 2002) 